\title{
Nephroprotective Effect of Sonchus oleraceus Extract against Kidney Injury Induced by Ischemia-Reperfusion in Wistar Rats
}

\author{
Liliana Torres-González, ${ }^{1}$ Eduardo Cienfuegos-Pecina, ${ }^{1}$ Marlene M. Perales-Quintana, ${ }^{2}$ \\ Gabriela Alarcon-Galvan $\left(\mathbb{D},{ }^{3}\right.$ Linda E. Muñoz-Espinosa, ${ }^{1}$ Edelmiro Pérez-Rodríguez, ${ }^{2}$ \\ and Paula Cordero-Pérez $\mathbb{i D}^{1}$
}

\author{
${ }^{1}$ Liver Unit, Department of Internal Medicine, University Hospital “Dr. José E. González”, Universidad Autónoma de Nuevo León, \\ Av. Gonzalitos No. 235 Col. Mitras Centro C.P., 64460 Monterrey, NL, Mexico \\ ${ }^{2}$ Transplant Service, University Hospital "Dr. José E. González”, Universidad Autónoma de Nuevo León, \\ Av. Gonzalitos No. 235 Col. Mitras Centro C.P., 64460 Monterrey, NL, Mexico \\ ${ }^{3}$ Basic Science Department, School of Medicine, UDEM, Universidad de Monterrey, Av. Ignacio Morones Prieto 4500 Pte., \\ Jesús M. Garza, C.P., 66238 San Pedro Garza García, NL, Mexico
}

Correspondence should be addressed to Paula Cordero-Pérez; paucordero@yahoo.com.mx

Received 21 August 2017; Revised 6 December 2017; Accepted 13 December 2017; Published 14 February 2018

Academic Editor: Hu Qin

Copyright @ 2018 Liliana Torres-González et al. This is an open access article distributed under the Creative Commons Attribution License, which permits unrestricted use, distribution, and reproduction in any medium, provided the original work is properly cited.

\begin{abstract}
Introduction. Kidney ischemia-reperfusion (I/R) injury is the main cause of delayed graft function in solid organ transplantation. Sonchus oleraceus is a plant with well-known antioxidant and anti-inflammatory activities; however, its effects on renal I/R are unknown. Objective. To evaluate whether S. oleraceus extract (S.O.e.) has nephroprotective activity in an I/R model in Wistar rats. Materials and Methods. Animal groups $(n=6)$ : sham, I/R $(45 \mathrm{~min} / 15 \mathrm{~h})$, S.O.e $(300 \mathrm{mg} / \mathrm{kg}$ p.o. $)$, and S.O.e + I/R $(300 \mathrm{mg} / \mathrm{kg}$, p.o.; $45 \mathrm{~min} / 15 \mathrm{~h}$ ). Renal function, proinflammatory cytokines, alanine aminotransferase, markers of oxidative stress, and histology were evaluated. Results. None of the mediators evaluated differed significantly between the S.O.e and sham groups. Levels of blood urea nitrogen (BUN), creatinine, malondialdehyde (MDA), and proinflammatory cytokines were higher, and superoxide dismutase (SOD) was lower in the I/R group than in the sham group. Histology showed tubular epithelial necrosis in the medulla and cortex in the I/R group. In the S.O.e + I/R group, S.O.e pretreatment attenuated the I/R-induced increases in BUN, creatinine, MDA, and proinflammatory cytokines induced, SOD was maintained, and histology showed discontinuous necrosis in the medulla but no necrosis in the cortex. Conclusions. S.O.e was neither hepatotoxic nor nephrotoxic. S.O.e. pretreatment showed a nephroprotective effect against I/R.
\end{abstract}

\section{Introduction}

Kidney injury caused by ischemia-reperfusion (I/R) is a significant clinical problem and is considered to be the main cause of acute renal failure, which can result from shock, partial nephrectomy, or renal transplantation and can lead to morbidity and mortality $[1,2]$. Multiple pathogenic factors contribute to the eventual death of kidney cells as a result of $\mathrm{I} / \mathrm{R}$, including excessive oxidative stress, actions of proinflammatory cytokines, recruitment of inflammatory cells, and apoptosis [2,3]. Excessive oxidative stress is caused mainly by reactive oxygen species (ROS) produced during reperfusion and released as part of the inflammatory response. ROS can damage cell organelles and change the oxidation-reduction balance. The action of antioxidants, such as reduced glutathione and enzymes such as superoxide dismutase (SOD), is essential to reducing tissue damage.

Plants have been shown to be potential therapeutic agents to protect against renal I/R. Experimental studies in rats have reported that the primary mechanism through which plant extracts prevent kidney damage induced by $I / R$ involves counteracting the effects of excessive oxidative stress through 
free radical-scavenging and antioxidant capacity $[4,5]$. Sonchus oleraceus is a plant of the Asteraceae family and is distributed worldwide. Many Sonchus species are used by diverse cultures for the treatment of stomach pain, hepatitis, infections, headache, rheumatism, cancer, warts, ulcers, spider and snake bites, and inflammation [6-9]. In Mexico, S. oleraceus is known as Achicoria dulce, cerraja, lechuguilla, muela de caballo, and falso diente de león [10]. Throughout the world, it is known as sow thistle or pūhā [11, 12]. Recent research has shown that an S. oleraceus extract (S.O.e) exhibits several types of bioactivity, including anxiolytic [6], anti-inflammatory $[7,9]$, antibacterial [8], antioxidant [8, $11,13,14]$, antitumor [15], antinociceptive [16], and antiaging [12] activities.

Given the reported antioxidant activity and potential pharmacological properties, the aim of the current investigation was to evaluate whether $S$. oleraceus has a nephroprotective effect against I/R-induced injury in Wistar rats.

\section{Material and Methods}

2.1. Extract Preparation. The plant was collected in García, NL, Mexico, during the summer of 2014 and authenticated, and a voucher specimen (UAN-2429) was deposited in the institutional herbarium located at the School of Biology of the Universidad Autónoma de Nuevo León. The S. oleraceus aerial part was dried at room temperature for 2 weeks and then finely ground. The extract was obtained using Soxhlet extraction. Briefly, $100 \mathrm{~g}$ of dried material was extracted in $1 \mathrm{~L}$ of ethanol for $5 \mathrm{~h}$, and the extracted material was filtered and concentrated under reduced pressure at $37^{\circ} \mathrm{C}$, dried in an oxygen-free environment at $37^{\circ} \mathrm{C}$, and stored at $4^{\circ} \mathrm{C}$ until use; the recovery was $3.3 \%$.

2.2. Animals. Animal procedures were performed in accordance with the proper use and care of laboratory animals and according to the specifications of the Mexican Official Norm NOM-062-ZOO-1999 and were approved by the ethics committee of our institution (HI17-00002). Experiments were performed using male Wistar rats weighing 200-300 g (Círculo A.D.N. S.A. de C.V., Mexico City, Mexico). Animals were kept under standard conditions such as a stable room temperature $\left(24 \pm 3^{\circ} \mathrm{C}\right)$ and $12 \mathrm{~h}$ light-dark cycle and had access to commercial rat pellets and water ad libitum.

2.3. Experimental Design. To evaluate whether treatment with S.O.e at a dose of $300 \mathrm{mg} / \mathrm{kg}$ could reduce kidney injury after $I / R$, the following experimental groups were evaluated ( $n=6$ per group).

The sham group was treated with the extract vehicle (3\% Tween-20) for 7 days, after which the rats received a sham laparotomy without affecting the renal pedicle.

The S.O.e group was treated with $300 \mathrm{mg} / \mathrm{kg}$ of extract for 7 days according to the report by Li et al. [9], after which the rats received the same surgical procedure as the sham group.

The I/R group was treated with the extract vehicle for 7 days, after which acute kidney injury was induced by I/R ( $45 \mathrm{~min}$ ischemia $+15 \mathrm{~h}$ reperfusion).
The S.O.e + I/R group was treated with $300 \mathrm{mg} / \mathrm{kg}$ of extract for 7 days, after which the kidney injury was induced by the same procedure as the I/R group.

2.4. Induction of Kidney Injury. Rats were anesthetized using xylazine (Sedaject; Vedilab S.A. de C.V. Reg. SAGARPA Q0088-122) by intraperitoneal injection at a dose of $10 \mathrm{mg} / \mathrm{kg}$ of body weight with ketamine as an analgesic (Anesket; PiSA Agropecuaria, S.A. de C.V. Reg. SAGARPA Q7833-028) by intraperitoneal injection at a dose of $100 \mathrm{mg} / \mathrm{kg}$ of body weight according to the suppliers' specifications.

The I/R and S.O.e + I/R groups received a laparotomy to expose both kidneys. Kidney injury was induced by ischemia caused by $45 \mathrm{~min}$ of occlusion of the renal pedicle used vascular clamps, after which the clamps were withdrawn and reperfusion was allowed for $15 \mathrm{~h}$. During this period, rats were allowed access to food and water ad libitum. For the sham and S.O.e groups, the surgical procedure involved a laparotomy without any occlusion.

Blood samples were taken from rats after the surgical procedure and centrifuged at $3500 \mathrm{rpm}$ for $15 \mathrm{~min}$. The serum was separated and was used to measure the levels of alanine aminotransferase (ALT), renal function markers, and proinflammatory cytokines. Kidney tissue samples were obtained immediately after the blood samples were taken. One part of the tissue was fixed in $10 \%$ formaldehyde for histopathological evaluation, and the other was frozen at $-80^{\circ} \mathrm{C}$ for measurement of malondialdehyde (MDA) and SOD levels.

2.5. Biochemical Analysis, Proinflammatory and Oxidative Stress Markers. Blood urea nitrogen (BUN), creatinine concentration, and ALT activity were determined by spectrophotometry (ILab Aries; Instrumentation Laboratory, Milan, Italy) using commercial kits (Instrumentation Laboratory) according to the supplier's specifications.

The concentrations of proinflammatory cytokines were measured using a commercial enzyme-linked immunosorbent assay for rat interleukin 6 (IL-6), interleukin 1-beta (IL-1 $\beta$ ), and tumor necrosis factor-alpha (TNF- $\alpha$ ) (PeproTech, Mexico City, Mexico). Avidin-horseradish peroxidase conjugate was used to oxidize 2,2'-azino-bis(3-ethylbenzothiazoline-6-sulfonic acid), which produced a chromogen whose concentration was proportional to the concentration of the cytokine being evaluated. The measurements were made spectrophotometry at $405 \mathrm{~nm}$.

The concentration of MDA, the final product of lipid peroxidation, was measured using a thiobarbituric acid-reactive substance (TBARS) assay using a TBARS Assay Kit (Cayman Chemical Company, Ann Arbor, MI, USA). To measure MDA concentration, $100 \mu \mathrm{L}$ of the supernatant from medium or standard, $100 \mu \mathrm{L}$ of sodium dodecyl sulfate, and $4 \mathrm{~mL}$ of the color reagent were added to each vial. The vial was heated at $100^{\circ} \mathrm{C}$ for $1 \mathrm{~h}$ and then immediately cooled in an ice bath and centrifuged at $11,000 \mathrm{rpm}$ for $15 \mathrm{~min}$ at $4^{\circ} \mathrm{C}$. Next, $150 \mu \mathrm{L}$ from each vial was transferred to each well in a microplate. The absorbance of the product was measured at a wavelength of $540 \mathrm{~nm}$ on a microplate reader. The extent of lipid peroxidation was quantified by estimating the MDA 


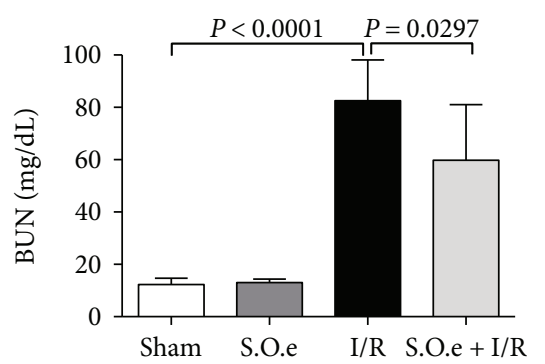

(a)

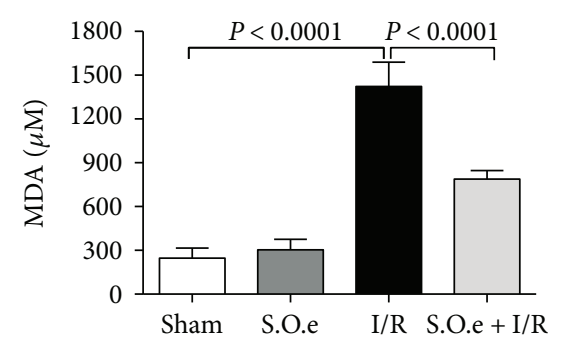

(c)

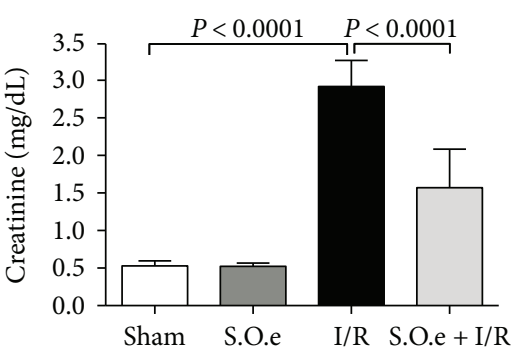

(b)

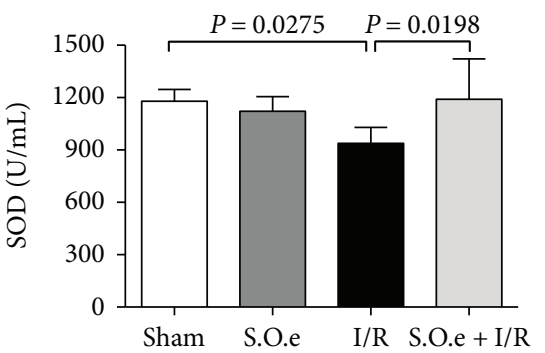

(d)

FIGURE 1: Changes in renal function tests and markers of oxidative stress. (a) BUN, (b) creatinine, (c) MDA, and (d) SOD levels before and after I/R. Values are expressed as mean \pm SD.

concentration. The results are expressed as micromoles of MDA equivalents formed per liter.

SOD activity was measured using a Superoxide Dismutase Assay kit (Cayman Chemical Company) and a colorimetric assay to measure the concentration of formazan crystals at $450 \mathrm{~nm}$. This assay uses a tetrazolium salt for the detection of superoxide radicals generated by xanthine oxidase and hypoxanthine. To measure SOD activity, $200 \mu \mathrm{L}$ of the diluted radical detector and $10 \mu \mathrm{L}$ of the supernatant of tissue homogenate or standard were added to each well of a 96-well plate, and $20 \mu \mathrm{L}$ of xanthine oxidase was added. Absorbance in the well was measured at a wavelength of $460 \mathrm{~nm}$ after $20 \mathrm{~min}$ on a microplate reader (Thermo Scientific Multiskan FC, Waltham, USA). The results are expressed as IU/mL. One IU of SOD is defined as the amount of enzyme needed to exhibit 50\% dismutation of the superoxide radical.

2.6. Evaluation of Renal Histopathology. Kidneys were fixed in a $10 \%$ buffered formaldehyde solution ( $\mathrm{pH} 7.4)$. A representative sample was taken from both kidneys of all rats in the four groups. The tissue was processed routinely and paraffin embedded. Paraffin blocks were cut using a microtome at a thickness of $4 \mu \mathrm{m}$, and the sections were deparaffinized, hydrated, and stained with hematoxylin and eosin (H\&E). The sections were examined under a microscope for the presence of indicators of cellular damage such as tubular necrosis and eosinophilic casts, which are regarded as semiquantitative measures. A scoring system was used to evaluate kidney histopathology as follows: no damage $=0$; mild damage $=1$ (unicellular patchy isolated damage); moderate damage $=2$ (damage $<25 \%) ;$ severe $=3$ (damage $25-50 \%)$; severe $=4$ (>50\% damage) [17].
2.7. Statistical Analysis. The data are expressed as mean \pm standard deviation (SD) and were analyzed by one-way analysis of variance followed by the Tukey test for multiple comparisons or Kruskal-Wallis nonparametric test using Prism software (v. 6.0; GraphPad, San Diego, CA, USA). Differences between means were considered significant at $p<0.05$.

\section{Results}

3.1. Study of the Toxicity of the Plant Extract In Vivo. There were no significant differences between the sham and S.O.e groups in the levels or activities of ALT ( $86 \pm 7$ IU/L versus $90 \pm 6 \mathrm{IU} / \mathrm{L}), \mathrm{BUN}(12 \pm 2 \mathrm{mg} / \mathrm{dL}$ versus $13 \pm 1 \mathrm{mg} / \mathrm{dL})$, creatinine serum $(0.53 \pm 0.33 \mathrm{mg} / \mathrm{dL}$ versus $0.50 \pm 0.22 \mathrm{mg} / \mathrm{dL})$, MDA $(247 \pm 20 \mu \mathrm{M}$ versus $304 \pm 21 \mu \mathrm{M})$, SOD $(1082 \pm 54 \mathrm{U} /$ $\mathrm{mL}$ versus $1179 \pm 28 \mathrm{U} / \mathrm{mL}$ ), and IL-6 (Figure 1, Table 1). The concentrations of IL- $1 \beta$ and TNF- $\alpha$ were significantly higher in the sham group than in the S.O.e group (Table 1).

3.2. Effect of S. oleraceus Extract on Kidney Injury Induced by $I / R$. The BUN and creatinine levels were significantly higher in the I/R group than in the sham group $(83 \pm 16 \mathrm{mg} / \mathrm{dL}$ versus $12 \pm 2 \mathrm{mg} / \mathrm{dL} ; 2.92 \pm 0.35 \mathrm{mg} / \mathrm{dL}$ versus $0.53 \pm 0.33 \mathrm{mg} / \mathrm{dL}$, respectively; $p<0.0001$ ) (Figure 1). In the group pretreated with $S$. oleraceus before ischemia (S.O.e $+\mathrm{I} / \mathrm{R}$ group), the increases in BUN and serum creatinine levels were significantly attenuated: $83 \pm 16 \mathrm{mg} / \mathrm{dL}$ versus $60 \pm 21 \mathrm{mg} / \mathrm{dL}$, respectively $(p=0.0297)$ and $2.92 \pm 0.35 \mathrm{mg} / \mathrm{dL}$ versus $1.57 \pm 0.51 \mathrm{mg} / \mathrm{dL}$, respectively $(p<0.0001)$ (Figure 1$)$.

MDA level was significantly higher in the $\mathrm{I} / \mathrm{R}$ group than in the sham group $(1422 \pm 166 \mu \mathrm{M}$ versus $247 \pm 20 \mu \mathrm{M}$; $p<0.0001)$. S. oleraceus treatment significantly attenuated the increase in MDA level in the S.O.e+I/R group 
TABLE 1: Concentrations of proinflammatory cytokines in the experimental groups.

\begin{tabular}{lccc}
\hline Experimental groups & $\begin{array}{c}\text { IL-6 } \\
(\mathrm{ng} / \mathrm{mL})\end{array}$ & $\begin{array}{c}\text { IL-1 } \beta \\
(\mathrm{ng} / \mathrm{mL})\end{array}$ & $\begin{array}{c}\text { TNF- } \alpha \\
(\mathrm{ng} / \mathrm{mL})\end{array}$ \\
\hline Sham & $0.14 \pm 0.03$ & $0.86 \pm 0.13$ & $0.42 \pm 0.07$ \\
I/R & $0.37 \pm 0.06^{*}$ & $1.36 \pm 0.09^{*}$ & $0.77 \pm 0.15^{*}$ \\
S.O.e & $0.13 \pm 0.05$ & $0.61 \pm 0.11^{*}$ & $0.29 \pm 0.10^{*}$ \\
S.O.e + I/R & $0.11 \pm 0.05^{* *}$ & $0.64 \pm 0.19^{* *}$ & $0.42 \pm 0.09^{* *}$ \\
\hline
\end{tabular}

Data are presented as mean \pm S.D. ${ }^{*}$ Sham versus study group $(P<0.004)$, ${ }^{* *} \mathrm{I} / \mathrm{R}$ versus S.O.e $+\mathrm{I} / \mathrm{R}(P<0.007)$.

compared with the $\mathrm{I} / \mathrm{R}$ group $(789 \pm 58 \mu \mathrm{M}$ versus $1422 \pm$ $166 \mu \mathrm{M} ; p<0.001$ ) (Figure 1).

SOD level was significantly lower in the I/R group than in the sham group $(959 \pm 88 \mathrm{U} / \mathrm{mL}$ versus $1082 \pm 54 \mathrm{U} / \mathrm{mL} ; p=$ $0.0275)$. In the S.O.e $+\mathrm{I} / \mathrm{R}$ group, SOD levels were preserved to compared at I/R group $(1191 \pm 231 \mathrm{U} / \mathrm{mL} ; p=0.0198)$ (Figure 1).

The TNF- $\alpha$, IL- $1 \beta$, and IL- 6 concentrations were significantly higher in the $\mathrm{I} / \mathrm{R}$ group than in the sham group $(p<0.004)$. The cytokine concentrations were significantly lower in the S.O.e $+\mathrm{I} / \mathrm{R}$ group than in the $\mathrm{I} / \mathrm{R}$ group $(p<0.007)$ (Table 1$)$.

3.3. Evaluation of Renal Histopathology. The scoring system used for evaluation of kidney histopathology is shown in Table 2 . The mean score for tissue damage was significantly higher in the I/R group than in the sham group. Kidneys of rats treated with S. oleraceus exhibited less damage, as shown by lower scores, compared with the I/R group. Light microscopic examination of H\&E-stained tissue sections showed normal renal parenchyma, tubules, and glomeruli in the sham and S.O.e groups. By contrast, kidney tissues from the I/R group showed tubular epithelium necrosis in the medulla and cortex. Kidney tissues from the S.O.e $+\mathrm{I} / \mathrm{R}$ group showed discontinuous necrosis in the marrow and conserved cortex (Figure 2).

\section{Discussion}

When an extract is proposed as a possible therapeutic strategy, it is necessary to demonstrate that it is not toxic. To rule out any possible hepatotoxic or nephrotoxic effects of the extract, we measured the levels of ALT, BUN, creatinine, SOD, and MDA in the S.O.e group. The extract had no measurable effects on these variables, as shown by the similar levels of these mediators in the treated and sham groups. This agrees with the findings by other investigations that $S$. oleraceus has no cytotoxic effect in vitro or in vivo $[9,18]$.

Renal ischemia cannot be prevented in some clinical situations such as renal transplantation, traumatic shock, sepsis, postpartum hemorrhage, or major surgery. I/Rinduced kidney injury occurs when the blood flow to an organ is stopped temporarily and blood is then reperfused with oxygenated blood to the organ. This process triggers the release of ROS, one of the main causes of the tissue injury
TABLE 2: Mean scores for total tissue damage in the experimental groups.

\begin{tabular}{lcc}
\hline \multirow{2}{*}{ Experimental groups } & \multicolumn{2}{c}{ Parameters } \\
& Tubular necrosis & Eosinophilia casts \\
\hline Sham & $0.50 \pm 0.75$ & $0.00 \pm 0.00$ \\
I/R & $4.00 \pm 0.00^{*}$ & $2.25 \pm 0.95^{*}$ \\
S.O.e & $0.50 \pm 0.54$ & $0.00 \pm 0.00$ \\
S.O.e + I/R & $2.77 \pm 0.66^{* *}$ & $1.44 \pm 0.52^{* *}$ \\
\hline
\end{tabular}

Data are presented as mean \pm S.D. ${ }^{*} P<0.05$ as compared with Sham, ${ }^{* *} P<0.05$ as compared with $\mathrm{I} / \mathrm{R}$.

caused by reperfusion $[2,19,20]$. This tissue injury stimulates an inflammatory response mediated mainly by neutrophils and macrophages, which then release proinflammatory mediators such as cytokines [1]. This inflammatory response directly affects renal function as shown by an increase in the serum concentrations of BUN and creatinine. Some plants with antioxidant activity have been reported to decrease the secondary damage caused by oxidative stress produced by kidney I/R (which affects kidney function) [21, 22]. In this study, we found that the pretreatment with S.O.e. attenuated the increases in serum of BUN and creatinine levels compared with those observed in the I/R group. This finding suggests that S.O.e. may have a nephroprotective effect, which may be related to its antioxidant activity as reported by others $[8,11,13,14,18,23]$.

Proinflammatory cytokines participate in an important pathway involved in I/R-induced renal injury. IL-6 release increases the degree of injury, dysfunction, and renal inflammation; this cytokine promotes the expression of adhesion molecules and consequent oxidative stress [24]. TNF- $\alpha$, a potent proinflammatory cytokine, has been shown to reduce glomerular perfusion by inducing the synthesis of vasoconstrictor and vasodilator mediators [25]. IL- $1 \beta$ has been described as a chemoattractant that recruits leukocytes to the areas of renal inflammation, which leads eventually to kidney damage [26]. Treatment with an extract of S. oleraceus has been reported to have an anti-inflammatory effect in several models. In a recent in vitro model of the RAW 264.7 mouse macrophage cell line, an extract of S. oleraceus had an anti-inflammatory effect after stimulation with lipopolysaccharide, as shown by significant decreases in the levels of IL- $1 \beta$, IL- 6 , and TNF- $\alpha$. This study also reported a decreased inflammatory response to in vivo xylene-induced edema with an extract dose of $300 \mathrm{mg} / \mathrm{kg}$ [9]. In our study, the significantly higher IL- $1 \beta$, IL- 6 , and TNF- $\alpha$ levels in the $\mathrm{I} / \mathrm{R}$ group than in the sham group indicated the presence of an inflammatory response. Pretreatment with S.O.e. at a dose of $300 \mathrm{mg} / \mathrm{kg}$ significantly attenuated this increase in IL- $1 \beta$, IL-6, and TNF- $\alpha$ levels in the S.O.e + I/R group through effects on the inflammatory response.

Recent phytochemical investigations of $S$. oleraceus have identified secondary metabolites such as sesquiterpene lactones, taraxasterol, luteolin, apigenin, caftaric acid, chicoric acid, villosol, ferulic acid, $\beta$-sitosterol, ursolic acid, rutin, $\beta$-daucosterin, and others $[9,13,27]$. Of these secondary metabolites, several bioactive molecules may be involved 


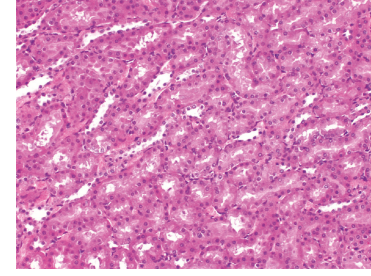

(a)

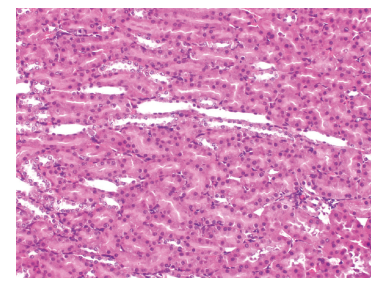

(c)

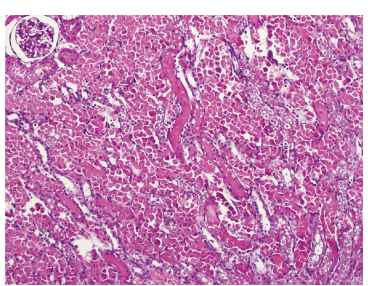

(b)

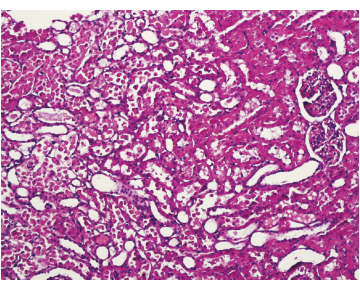

(d)

Figure 2: Hematoxylin and eosin (H\&E) staining of kidney tissue. (a) Sham group, normal kidney tissue structure ( $\times 10)$; (b) I/R group, diffuse tubular necrosis and abundant protein-like intratubular eosinophilic cylinders $(\times 10)$; (c) S.O.e group, sham-like morphology; (d) S.O.e + IR group, significant increase in renal histopathological findings $(\times 10)$.

in vasoprotection from the endothelial injury induced by I/R. Examples include rutin, which exhibits anti-inflammatory activity because of its free radical-scavenging and antioxidant capacities [28]; $\beta$-sitosterol, which significantly inhibits the TNF- $\alpha$-induced expression of adhesion molecules that play key roles in the inflammatory process and interfere with multiple signaling pathways including cell cycle, apoptosis, proliferation, and metastasis [29, 30]; apigenin, which attenuates the inhibition of vasorelaxation induced by pyrogallol [31] and exerts anti-inflammatory activity by modulating nuclear factor $\kappa \mathrm{B}$ activity, reducing inflammatory cytokine production and limiting neutrophil migration toward the inflammatory microenvironment [32]; and luteolin, a potent inhibitor of inflammation that may also help to ensure endothelial integrity [33]. These actions suggest that the anti-inflammatory effect observed in the S.O.e + I/R group may relate to the presence of some of these molecules described in this plant.

Reperfusion after ischemia increases the release of ROS, which are important effectors of cellular injury [18]. Free radicals participate in the physiopathology of renal I/R injury [2]. Cellular antioxidant enzymes such as SOD block the free radical effect; however, overwhelming of these protective activities by excessive production of free radicals causes lipid peroxidation, whose end product is MDA [34, 35]. In our study, treatment with $S$. oleraceus attenuated the oxidative injury produced by renal $I / R$, as shown by the increase in SOD activity and decrease in MDA activity. This effect may reflect the antioxidant activities described for some molecules contained in extracts of $S$. oleraceus as rutin, luteolin, and chicoric acid $[11,13]$.

Several studies have reported characteristic lesions of I/Rinduced renal injury $[1,3-5,19-21]$. In our study, ischemia for $45 \mathrm{~min}$ and reperfusion of $15 \mathrm{~h}$ caused damage to renal tissue, as shown by measures of renal dysfunction such as diffuse tubular necrosis and abundant protein-like intratubular eosinophilic cylinders. S.O.e. attenuated the renal injury produced by the $I / R$, as shown by discontinuous necrosis in the medulla and conserved cortex.

\section{Conclusion}

Our results indicate that S.O.e. was neither hepatotoxic nor nephrotoxic and that pretreatment with S.O.e. markedly attenuated postischemic damage to rat kidneys. Treatment with S.O.e. attenuated the increase in proinflammatory cytokine levels and markers of renal damage and oxidative stress. Our study provides a basis for further identification of which molecules are responsible for this apparent nephroprotective activity of $S$. oleraceus. This is the first report of nephroprotective activity of S.O.e against I/R-induced injury.
Abbreviations
I/R: Ischemia/reperfusion
S.O.e.: Sonchus oleraceus extract
ROS: Reactive oxygen species
SOD: Superoxide dismutase
MDA: Malondialdehyde
ALT: Alanine aminotransferase
BUN: Blood urea nitrogen
IL-6: Interleukin 6
IL-1 $\beta$ : Interleukin 1-beta
TNF- $\alpha$ : Tumor necrosis-alpha.

\section{Conflicts of Interest}

The authors declare that there is no conflict of interest regarding the publication of this article.

\section{References}

[1] M. Andreucci, T. Faga, A. Pisani, M. Perticone, and A. Michael, "The ischemic/nephrotoxic acute kidney injury 
and the use of renal biomarkers in clinical practice," European Journal of Internal Medicine, vol. 39, pp. 1-8, 2017.

[2] M. Salvadori, G. Rosso, and E. Bertoni, "Update on ischemiareperfusion injury in kidney transplantation: pathogenesis and treatment," World Journal of Transplantation, vol. 5, no. 2, pp. 52-67, 2015.

[3] B. Dorweiler, D. Pruefer, T. B. Andrasi et al., "Ischemia-reperfusion injury," European Journal of Trauma and Emergency Surgery, vol. 33, no. 6, pp. 600-612, 2007.

[4] H. Hosseinzadeh, H. R. Sadeghnia, T. Ziaee, and A. Danaee, "Protective effect of aqueous saffron extract (Crocus sativus L.) and crocin, its active constituent, on renal ischemiareperfusion-induced oxidative damage in rats," Journal of Pharmacy \& Pharmaceutical Sciences, vol. 8, no. 3, pp. 387-393, 2005.

[5] T. Nakagawa, T. Yokozawa, A. Satoh, and H. Y. Kim, "Attenuation of renal ischemia-reperfusion injury by proanthocyanidin-rich extract from grape seeds," Journal of Nutritional Science and Vitaminology, vol. 51, no. 4, pp. 283-286, 2005.

[6] F. Cardoso Vilela, R. Soncini, and A. Giusti-Paiva, "Anxiolyticlike effect of Sonchus oleraceus L. in mice," Journal of Ethnopharmacology, vol. 124, no. 2, pp. 325-327, 2009.

[7] F. C. Vilela, A. D. Bitencourt, L. D. M. Cabral, L. S. Franqui, R. Soncini, and A. Giusti-Paiva, "Anti-inflammatory and antipyretic effects of Sonchus oleraceus in rats," Journal of Ethnopharmacology, vol. 127, no. 3, pp. 737-741, 2010.

[8] D.-Z. Xia, X.-F. Yu, Z.-Y. Zhu, and Z.-D. Zou, "Antioxidant and antibacterial activity of six edible wild plants (Sonchus spp.) in China," Natural Product Research, vol. 25, no. 20, pp. 1893-1901, 2011.

[9] Q. Li, D.-D. Dong, Q.-P. Huang et al., “The anti-inflammatory effect of Sonchus oleraceus aqueous extract on lipopolysaccharide stimulated RAW 264.7 cells and mice," Pharmaceutical Biology, vol. 55, no. 1, pp. 799-809, 2017.

[10] G. Calderón de Rzedowski, "Familia Compositae Tribu Lactuceae," Flora del Bajío y de Regiones Adyacentes, vol. 1, no. 54, pp. 1-55, 1997.

[11] A. McDowell, S. Thompson, M. Stark, Z. Q. Ou, and K. S. Gould, "Antioxidant activity of puha (Sonchus oleraceus L.) as assessed by the cellular antioxidant activity (CAA) assay," Phytotherapy Research, vol. 25, no. 12, pp. 1876-1882, 2011.

[12] Z.-Q. Ou, T. Rades, and A. McDowell, "Anti-ageing effects of Sonchus oleraceus L. (pūhā) leaf extracts on $\mathrm{H}_{2} \mathrm{O}_{2}$-induced cell senescence," Molecules, vol. 20, no. 3, pp. 4548-4564, 2015.

[13] Z.-Q. Ou, D. M. Schmierer, T. Rades, L. Larsen, and A. McDowell, "Application of an online post-column derivatization HPLC-DPPH assay to detect compounds responsible for antioxidant activity in Sonchus oleraceus L. leaf extracts," Journal of Pharmacy and Pharmacology, vol. 65, no. 2, pp. 271-279, 2013.

[14] J. Yin, G.-J. Kwon, and M.-H. Wang, "The antioxidant and cytotoxic activities of Sonchus oleraceus L. extracts," Nutrition Research and Practice, vol. 1, no. 3, pp. 189-194, 2007.

[15] T. Huyan, Q. Li, Y.-L. Wang et al., "Anti-tumor effect of hot aqueous extracts from Sonchus oleraceus (L.) L. and Juniperus sabina $\mathrm{L}$ - two traditional medicinal plants in China," Journal of Ethnopharmacology, vol. 185, pp. 289-299, 2016.

[16] F. C. Vilela, M. de Mesquita Padilha, L. dos Santos-e-Silva, G. Alves-da-Silva, and A. Giusti-Paiva, "Evaluation of the antinociceptive activity of extracts of Sonchus oleraceus L. in mice,"
Journal of Ethnopharmacology, vol. 124, no. 2, pp. 306-310, 2009.

[17] S. Kobuchi, T. Shintani, T. Sugiura et al., "Renoprotective effects of $\gamma$-aminobutyric acid on ischemia/reperfusioninduced renal injury in rats," European Journal of Pharmacology, vol. 623, no. 1-3, pp. 113-118, 2009.

[18] C. M. Teugwa, P. C. Mejiato, D. Zofou, B. T. Tchinda, and F. F. Boyom, "Antioxidant and antidiabetic profiles of two African medicinal plants: Picralima nitida (Apocynaceae) and Sonchus oleraceus (Asteraceae)," BMC Complementary and Alternative Medicine, vol. 13, no. 1, p. 175, 2013.

[19] D. N. Granger, "Role of xanthine oxidase and granulocytes in ischemia-reperfusion injury," American Journal of Physiology - Heart and Circulatory Physiology, vol. 255, no. 6, pp. H1269-H1275, 1988.

[20] C. R. B. Welbourn, G. Goldman, I. S. Paterson, C. R. Valeri, D. Shepro, and H. B. Hechtman, "Pathophysiology of ischaemia reperfusion injury: central role of the neutrophil," British Journal of Surgery, vol. 78, no. 6, pp. 651-655, 1991.

[21] S. C. Ashtiyani, M. Zohrabi, A. Hassanpoor, N. Hosseini, and S. Hajihashemi, "Oral administration of the aqueous extract of Rosmarinus officinalis in rats before renal reperfusion injury," vol. 7, no. 5, pp. 367-375, 2013.

[22] E. M. El Morsy, M. A. E. Ahmed, and A. A. E. Ahmed, “Attenuation of renal ischemia/reperfusion injury by açaí extract preconditioning in a rat model," Life Sciences, vol. 123, pp. 35-42, 2015.

[23] S. M. M. R. Mawalagedera, Z.-Q. Ou, A. McDowell, and K. S. Gould, "Effects of boiling and in vitro gastrointestinal digestion on the antioxidant activity of Sonchus oleraceus leaves," Food \& Function, vol. 7, no. 3, pp. 1515-1522, 2016.

[24] N. S. Patel, P. K. Chatterjee, R. Di Paola et al., "Endogenous interleukin-6 enhances the renal injury, dysfunction, and inflammation caused by ischemia/reperfusion," Journal of Pharmacology and Experimental Therapeutics, vol. 312, no. 3, pp. 1170-1178, 2005.

[25] K. K. Donnahoo, X. Meng, A. Ayala, M. P. Cain, A. H. Harken, and D. R. Meldrum, "Early kidney TNF- $\alpha$ expression mediates neutrophil infiltration and injury after renal ischemia-reperfusion," American Journal of Physiology - Regulatory, Integrative and Comparative Physiology, vol. 277, no. 3, pp. R922-R929, 1999.

[26] M.Haq, J. Norman, S. R. Saba, G. Ramirez, and H. Rabb, “Role of IL-1 in renal ischemic reperfusion injury," Journal of the American Society of Nephrology, vol. 9, no. 4, pp. 614-619, 1998.

[27] J. Yin, C.-L. Si, and M.-H. Wang, "Antioxidant activity of flavonoids and their glucosides from Sonchus oleraceus L.," Journal of Applied Biological Chemistry, vol. 51, no. 2, pp. 57-60, 2008.

[28] H. Hosseinzadeh and M. Nassiri-Asl, "Review of the protective effects of rutin on the metabolic function as an important dietary flavonoid," Journal of Endocrinological Investigation, vol. 37, no. 9, pp. 783-788, 2014.

[29] P. Gupta, S. Balwani, S. Kumar et al., " $\beta$-sitosterol among other secondary metabolites of Piper galeatum shows inhibition of TNF $\alpha$-induced cell adhesion molecule expression on human endothelial cells," Biochimie, vol. 92, no. 9, pp. 1213-1221, 2010.

[30] M. S. Bin Sayeed and S. S. Ameen, "Beta-Sitosterol: a promising but orphan nutraceutical to fight against cancer," Nutrition and Cancer, vol. 67, no. 8, pp. 1216-1222, 2015. 
[31] B.-h. Jin, L.-b. Qian, S. Chen et al., "Apigenin protects endothelium-dependent relaxation of rat aorta against oxidative stress," European Journal of Pharmacology, vol. 616, no. 1-3, pp. 200-205, 2009.

[32] C. Nicholas, S. Batra, M. A. Vargo et al., "Apigenin blocks lipopolysaccharide-induced lethality in vivo and proinflammatory cytokines expression by inactivating NF- $\kappa \mathrm{B}$ through the suppression of p65 phosphorylation," The Journal of Immunology, vol. 179, no. 10, pp. 7121-7127, 2007.

[33] Z. Jia, P. Nallasamy, D. Liu et al., "Luteolin protects against vascular inflammation in mice and TNF-alpha-induced monocyte adhesion to endothelial cells via suppressing IKB $\alpha /$ NF- $\kappa \mathrm{B}$ signaling pathway," The Journal of Nutritional Biochemistry, vol. 26, no. 3, pp. 293-302, 2015.

[34] M. Cakir, H. Duzova, A. Taslidere, G. Orhan, and F. Ozyalin, "Protective effects of salusin- $\alpha$ and salusin- $\beta$ on renal ischemia/reperfusion damage and their levels in ischemic acute renal failure," Biotechnic \& Histochemistry, vol. 92, no. 2, pp. 122-133, 2017.

[35] M. Yin, M. D. Wheeler, H. D. Connor et al., "Cu/Zn-superoxide dismutase gene attenuates ischemia-reperfusion injury in the rat kidney," Journal of the American Society of Nephrology, vol. 12 , no. 12 , pp. 2691-2700, 2001. 


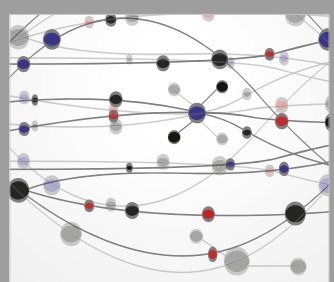

The Scientific World Journal
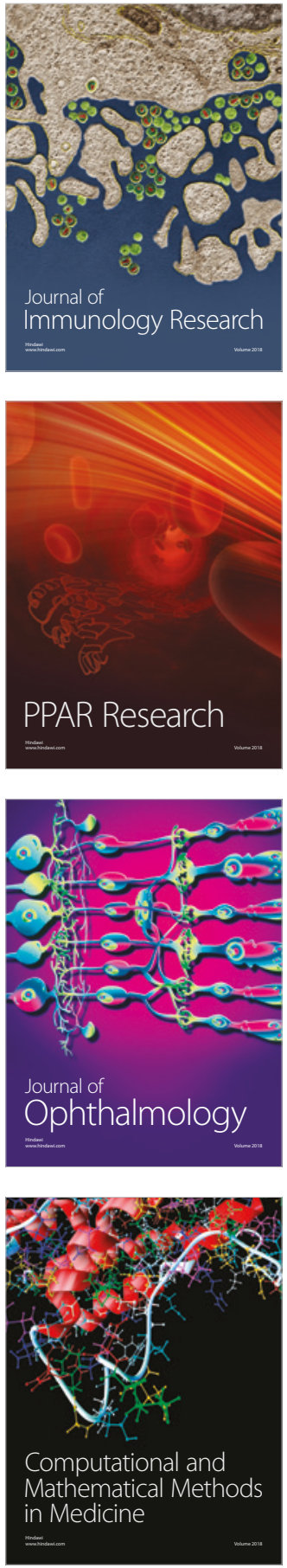

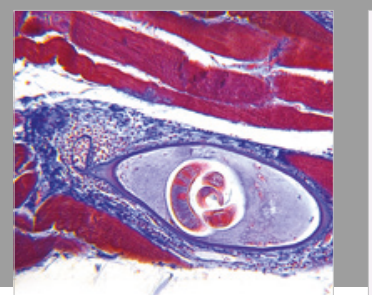

Gastroenterology Research and Practice

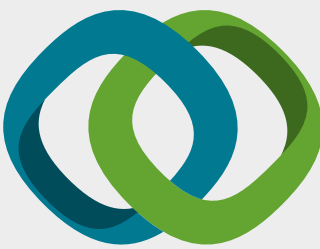

\section{Hindawi}

Submit your manuscripts at

www.hindawi.com
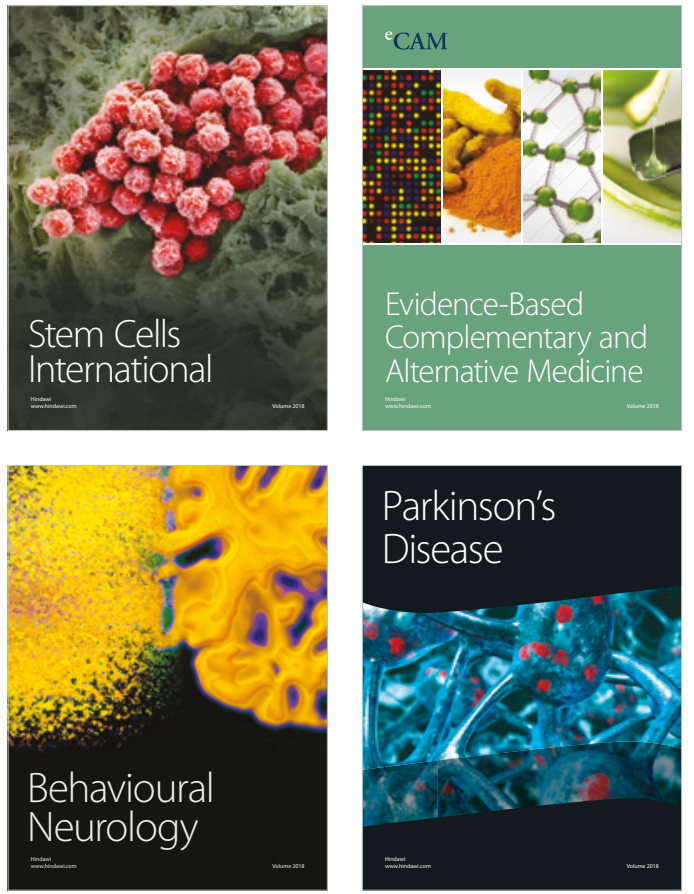

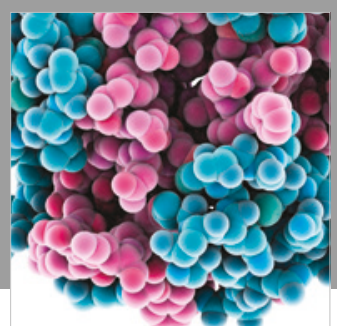

ournal of

Diabetes Research

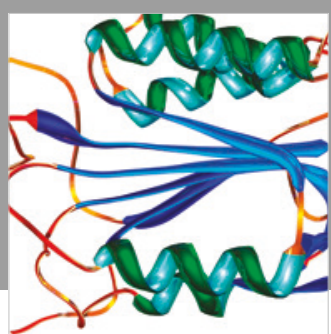

Disease Markers
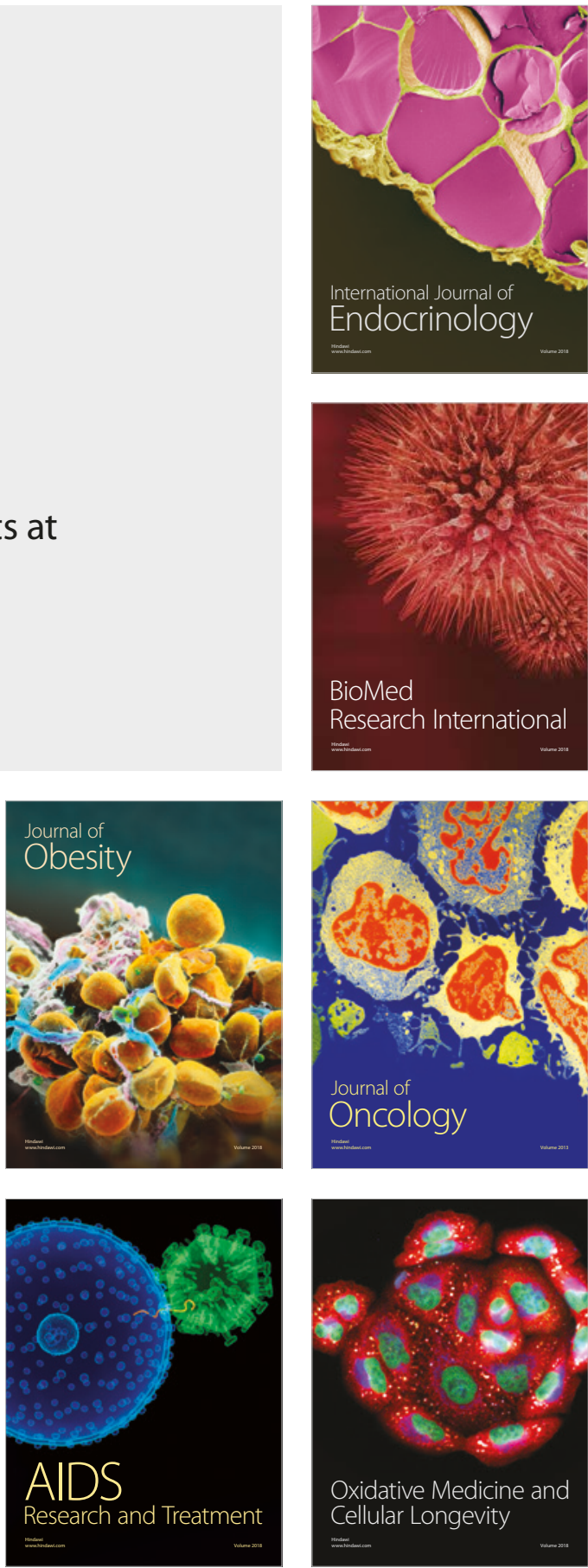